\title{
Protective Effects of Educational Attainment Against Cigarette Smoking; Diminished Returns of American Indians and Alaska Natives in the National Health Interview Survey
}

\author{
Shervin Assari ${ }^{*}$, Mohsen Bazargan ${ }^{1,2}$ \\ ${ }^{1}$ Department of Family Medicine, Charles R. Drew University of Medicine and Science, Los Angeles, USA \\ ${ }^{2}$ Department of Family Medicine, UCLA, Los Angeles, USA
}

Corresponding Author: Shervin Assari, MD, MPH, Department of Family Medicine, Charles R. Drew University of Medicine and Science, Los Angeles, USA. Tel: +1-7343632678, Email: assari@umich.edu

Received June 18, 2019; Accepted September 8, 2019; Online Published September 25, 2019

\begin{abstract}
Introduction: Although educational attainment is protective against health risk behaviors such as smoking, the Minorities' Diminished Returns theory posits that these protective effects are smaller for ethnic minorities than majority groups. This study compared the effects of educational attainment on the smoking status of American Indian/Alaska Native (AIAN) and White adults.

Methods: Data came from the National Health Interview Survey (NHIS - 2015). A total number of 21114 individuals entered the current analysis. The independent variable was years of schooling. The dependent variable was current smoking status. Age, gender, region, marital status, and employment were the covariates. Ethnicity was the moderator.

Results: Overall, educational attainment was inversely associated with current smoking. Ethnicity showed a significant interaction with educational attainment suggesting that the protective effects of educational attainment against smoking are smaller for AIANs than for Whites.

Conclusion: In the United States, while educational attainment helps individuals stay healthy by avoiding high risk behaviors such as smoking, this effect is smaller for AIANs than Whites, resulting in additional risk of smoking in highly educated AIANs. To reduce ethnic disparities in tobacco use, it is important to go beyond SES inequalities and investigate why high SES ethnic minorities remain at high risk of tobacco use.

Keywords: Population Groups, American Indian/Alaska Native (AIAN), Socioeconomic Position, Socioeconomic Status, Education, Smoking
\end{abstract}

Citation: Assari S, Bazargan M. Protective effects of educational attainment against cigarette smoking; diminished returns of American Indians and Alaska natives in the National Health Interview Survey. Int J Travel Med Glob Health. 2019;7(3):105-110. doi:10.15171/ijtmgh.2019.22.

\section{Introduction}

Pervasive disparities in the burden of tobacco use by race/ ethnicity ${ }^{1-5}$ and socioeconomic status (SES) $)^{6-8}$ exist in the US. Despite an overall decline in tobacco use, disparities in SES have increased. ${ }^{8-10}$ Between 1966 and 2015, smoking declined by $83 \%$ in individuals with a college degree, but the decline for individuals without a high school diploma was almost half that figure (40\%). A large proportion of such disparities may not be due to individuals making poor choices, but to higher exposure due to predatory marketing. ${ }^{11-13}$ Low SES individuals and ethnic minorities are at an increased risk for point-ofsale advertising, retail display, coupons, and discounts. ${ }^{14}$ The result is their increasing vulnerability ${ }^{15}$ such as higher rates of initiation combined with low access to cessation. ${ }^{3,16,17}$
The Minorities' Diminished Returns (MDRs) theory proposes that at least some of the ethnic disparities in tobacco use is due to "less than expected" protective effects of SES on tobacco use in minority populations. This suggests: (a) ethnic disparities in tobacco use are not all due to SES gaps, but also because of differential health gains that follow high SES for ethnic groups; and (b) the ethnic gap in tobacco use widens at higher SES levels, which emphasizes a need to address ethnic disparities in tobacco use across all SES levels.

The current study was conducted to compare American Indian/Alaska Native (AIAN) and White individuals for the effect of educational attainment, one of the main SES indicators, on tobacco use. It was hypothesized that the protective effects of educational attainment would be smaller

Copyright $\odot 2019$ The Author(s). This is an open-access article distributed under the terms of the Creative Commons Attribution License (http:// creativecommons.org/licenses/by/4.0), which permits unrestricted use, distribution, and reproduction in any medium, provided the original work is properly cited. 
for AIANs than for Whites. That is, MDRs were expected to also be relevant to AIANs. As similar patterns are shown for Blacks and Hispanics, ${ }^{18-29}$ the replication of the same patterns in AIANs would suggest that MDRs are not because of groups' or individuals' characteristics but society's differential treatment of all minority groups. As the US society marginalizes nonWhite people, MDRs result in worse than expected health outcomes among highly educated non-Whites.

\section{Methods}

\section{Design and Settings}

This is a secondary analysis of the NHIS data. Funded by the CDC, NHIS is one of the main national health surveys of Americans. This large nationally representative crosssectional study is one of the main sources of information regarding the health of the American population. Data used in this study were was collected in 2015.

\section{Data Retrieval}

In this study, the publicly available NHIS data set, downloaded from the NHIS website, was used. Personal, individual, and cancer data sets were merged using subject and family IDs. The current analysis included only 21114 adults who were either Whites or AIANs.

\section{Sample and Sampling}

The NHIS population was the 1) civilian, 2) noninstitutionalized US population, 3) 18+ years of age. The NHIS uses a multistage, clustered, stratified area probability sample design. In the NHIS, the probability sampling units (PSUs) are counties or groups of smaller counties.

\section{Analytical Sample}

The current analysis is limited to adults who were either White or AIAN and had valid data on tobacco use. The final analytical sample was 21114 adults.

\section{Study Variables}

The study variables included demographic factors (age and gender), ethnicity, educational attainment, employment, marital status, region, and tobacco use, all measured at the individual level.

Educational Attainment. Educational attainment was a continuous measure varying from 0 to 36 years.

Ethnicity. Ethnicity was self-identified and was AIAN versus White (Americans with European decent).

Current Smoking. The main outcome was current smoking status. Smoking was self-reported (smoked 100 cigarettes, smokes currently, and smokes daily).

Demographic Characteristics. Confounders were age, gender, marital status, employment status, and region. Age was a continuous measure. Gender was a dichotomous variable (male 1 female 0 ). Marital status was self-reported and a dichotomous variable. Employment status was a dichotomous variable: 1 = employed last week, $0=$ unemployed last week. Region was a 4-level categorical variable: 1) Northeast, 2) Midwest, 3) South, and 4) West.
Data Analytical Plan

Data was analyzed using SPSS 23.0 (IBM Corporation, Armonk, NY, USA). Survey weights were accommodated using SPSS 23.0. First, the distribution of our categorical and continuous variables was examined. Then, Pearson correlation tests were used to explore unadjusted correlations between the study constructs. To perform multivariable analysis, binary logistic regression was applied; however, collinearity between independent variables was first ruled out. Models were run in the pooled sample and each ethnic group.

\section{Results}

\section{Descriptive Statistics}

This study included 21,114 American adults who were either White $(n=20,855)$ or AIAN $(n=259)$. Table 1 shows the descriptive statistics of the overall sample as well as for Whites and AIANs. Current smoking was more common in AIANs than Whites (26.1 vs $16.7, P<0.05)$.

Multivariable models in the pooled sample

Table 2 presents the summary of the results of logistic regression models with educational attainment as the independent variable and current smoking as the dependent variable. Both models were estimated in the overall sample. Model 1 only entered the main effects of educational attainment, ethnicity, and covariates. Model 2 also added an interaction term between ethnicity and educational attainment. Based on Model 1, high educational attainment was associated with lower odds of current smoking. Model 2 showed significant interactions between ethnicity and educational attainment on

Table 1. Descriptive Statistics in the Overall Sample

\begin{tabular}{|c|c|c|c|c|c|c|}
\hline & \multicolumn{2}{|c|}{ All } & \multicolumn{2}{|c|}{ White } & \multicolumn{2}{|c|}{ AIAN } \\
\hline & Mean & SD & Mean & SD & Mean & SD \\
\hline Age* & 52.28 & 18.47 & 52.36 & 18.46 & 45.83 & 17.56 \\
\hline \multirow[t]{2}{*}{ Educational Attainment* } & 15.64 & 2.74 & 15.66 & 2.74 & 14.42 & 2.85 \\
\hline & $\mathbf{n}$ & $\%$ & $\mathbf{n}$ & $\%$ & $\mathbf{n}$ & $\%$ \\
\hline \multicolumn{7}{|l|}{ Gender } \\
\hline Women & 11402 & 54.0 & 11262 & 54.0 & 140 & 54.1 \\
\hline Men & 9712 & 46.0 & 9593 & 46.0 & 119 & 45.9 \\
\hline \multicolumn{7}{|l|}{ Marital Status* } \\
\hline Not Married & 11143 & 52.8 & 10964 & 52.6 & 179 & 69.1 \\
\hline Married & 9971 & 47.2 & 9891 & 47.4 & 80 & 30.9 \\
\hline \multicolumn{7}{|l|}{ Employment* } \\
\hline Unemployed & 9688 & 45.9 & 10964 & 52.6 & 179 & 69.1 \\
\hline Employed & 11426 & 54.1 & 9891 & 47.4 & 80 & 30.9 \\
\hline \multicolumn{7}{|l|}{ Region } \\
\hline Northeast & 3792 & 18.0 & 9552 & 45.8 & 136 & 52.5 \\
\hline Midwest & 5521 & 26.1 & 11303 & 54.2 & 123 & 47.5 \\
\hline South & 6425 & 30.4 & 11262 & 54.0 & 140 & 54.1 \\
\hline West & 5376 & 25.5 & 9593 & 46.0 & 119 & 45.9 \\
\hline
\end{tabular}

Source: National Health Interview Survey (NHIS 2015).

AIAN: American Indian/Alaska Native.

$* P<0.05$ for comparison of Whites and AIANs. 
Table 2. Logistic Regression in the Pooled Sample

\begin{tabular}{|c|c|c|c|c|}
\hline & B (SE) & OR & $95 \% \mathrm{Cl}$ & $P$ \\
\hline \multicolumn{5}{|l|}{ Model 1 (AII) } \\
\hline Ethnicity (AIAN) & $0.11(0.15)$ & 1.12 & $0.83-1.51$ & 0.453 \\
\hline Gender (Male) & $0.11(0.04)$ & 1.12 & $1.04-1.21$ & 0.003 \\
\hline Age & $-0.02(0.00)$ & 0.98 & $0.98-0.98$ & $<0.001$ \\
\hline Education & $-0.20(0.01)$ & 0.82 & $0.81-0.83$ & $<0.001$ \\
\hline Married & $-0.53(0.04)$ & 0.59 & $0.54-0.63$ & $<0.001$ \\
\hline Employed & $-0.10(0.04)$ & 0.91 & $0.83-0.99$ & 0.024 \\
\hline Region & & & & 0.021 \\
\hline Midwest & $0.16(0.06)$ & 1.17 & $1.04-1.31$ & 0.008 \\
\hline South & $0.14(0.06)$ & 1.15 & $1.03-1.29$ & 0.014 \\
\hline West & $0.06(0.06)$ & 1.06 & $0.94-1.19$ & 0.348 \\
\hline Constant & $2.70(0.14)$ & 14.85 & & $<0.001$ \\
\hline \multicolumn{5}{|l|}{ Model 2 (AII) } \\
\hline Ethnicity (AIAN) & $-1.96(0.74)$ & 0.14 & $0.03-0.61$ & 0.008 \\
\hline Gender (Male) & $0.11(0.04)$ & 1.12 & $1.04-1.21$ & 0.003 \\
\hline Age & $-0.02(0.00)$ & 0.98 & $0.98-0.98$ & $<0.001$ \\
\hline Education & $-0.20(0.01)$ & 0.82 & $0.81-0.83$ & $<0.001$ \\
\hline Married & $-0.53(0.04)$ & 0.59 & $0.54-0.63$ & $<0.001$ \\
\hline Employed & $-0.10(0.04)$ & 0.91 & $0.83-0.99$ & 0.025 \\
\hline Region & & & & 0.021 \\
\hline Midwest & $0.16(0.06)$ & 1.17 & $1.04-1.32$ & 0.008 \\
\hline South & $0.14(0.06)$ & 1.15 & $1.03-1.29$ & 0.015 \\
\hline West & $0.06(0.06)$ & 1.06 & $0.94-1.19$ & 0.336 \\
\hline $\begin{array}{l}\text { Ethnicity }(\mathrm{AIAN}) \times \text { Educational } \\
\text { Attainment }\end{array}$ & $0.15(0.05)$ & 1.16 & $1.05-1.28$ & 0.004 \\
\hline Constant & $2.74(0.14)$ & 15.43 & & $<0.001$ \\
\hline
\end{tabular}

Source: the National Health Interview Survey (NHIS 2015).

AIAN: American Indian/Alaska Native, SE: standard error; Cl: confidence interval; OR: odds ratio.

Outcome: Current smoking

$P<0.05$ is significant.

$\mathrm{SE}=0.00$ for age is of rounding

current smoking, suggesting that high educational attainment has smaller protective effects on current smoking for AIANs than Whites.

\section{Multivariable Models by Ethnicity}

Table 3 presents a summary of the results of two additional logistic regression models with educational attainment as the independent variable and smoking status as the outcome. Based on Model 3, high educational attainment in Whites was associated with lower odds of current smoking. Based on Model 4, educational attainment was not associated with smoking status in AIANs.

\section{Discussion}

The current study showed two findings. First, overall, highly educated people were less likely to smoke. Second, ethnicity altered the effect of educational attainment on smoking status with educational attainment showing smaller protective effects against smoking for AIANs than Whites.

Built on our previous work on MDRs, highly educated,
Table 3. Logistic Regression in the Ethnic Groups

\begin{tabular}{|c|c|c|c|c|}
\hline & B (SE) & OR & $95 \%$ CI For OR & $\boldsymbol{P}$ \\
\hline \multicolumn{5}{|c|}{ Model 3 (Whites) } \\
\hline Gender (Male) & $0.11(0.04)$ & 1.12 & $1.04-1.21$ & 0.004 \\
\hline Age & $-0.02(0.00)$ & 0.98 & $0.98-0.98$ & $<0.001$ \\
\hline Education & $-0.20(0.01)$ & 0.82 & $0.81-0.83$ & $<0.001$ \\
\hline Married & $-0.53(0.04)$ & 0.59 & $0.54-0.63$ & $<0.001$ \\
\hline Employed & $-0.09(0.04)$ & 0.91 & $0.84-1.00$ & 0.043 \\
\hline Region & & & & 0.021 \\
\hline Midwest & $0.16(0.06)$ & 1.17 & $1.04-1.32$ & 0.008 \\
\hline South & $0.15(0.06)$ & 1.16 & $1.04-1.30$ & 0.011 \\
\hline West & $0.07(0.06)$ & 1.07 & $0.95-1.21$ & 0.275 \\
\hline Constant & $2.73(0.14)$ & 15.38 & & $<0.001$ \\
\hline \multicolumn{5}{|c|}{ Model 4 (AIANs) } \\
\hline Gender (Male) & $0.17(0.30)$ & 1.18 & $0.66-2.13$ & 0.580 \\
\hline Age & $-0.02(0.01)$ & 0.98 & $0.96-1.00$ & 0.028 \\
\hline Education & $-0.03(0.05)$ & 0.97 & $0.88-1.08$ & 0.635 \\
\hline Married & $-0.48(0.37)$ & 0.62 & $0.30-1.27$ & 0.189 \\
\hline Employed & $-0.52(0.32)$ & 0.60 & $0.32-1.11$ & 0.103 \\
\hline Region & & & & 0.466 \\
\hline Midwest & $-0.08(0.58)$ & 0.92 & $0.30-2.86$ & 0.888 \\
\hline South & $-0.60(0.59)$ & 0.55 & $0.17-1.76$ & 0.312 \\
\hline West & $-0.53(0.54)$ & 0.59 & $0.20-1.69$ & 0.324 \\
\hline Constant & $0.94(1.05)$ & 2.56 & & 0.370 \\
\hline
\end{tabular}

Source: the National Health Interview Survey (NHIS 2015).

AIAN: American Indian/Alaska Native, SE: standard error; Cl: confidence interval; OR: odds ratio.

Outcome: Current smoking.

$P<0.05$ is significant.

$\mathrm{SE}=0.00$ for age is of rounding.

high-income, and employed Blacks and Hispanics are at an increased risk of substance use compared to high SES Whites. ${ }^{19,30-32}$ We also found that highly educated AIANs remain at high risk for smoking. These patterns are all similar and due to weaker associations between SES indicators and behavioral outcomes for non-Whites than Whites.

This is the first study to show MDRs for AIANs. The effects of educational attainment, income, marital status, and employment on obesity, depression, anxiety, self-rated health, and chronic disease are smaller for Blacks and Hispanics than Whites. ${ }^{18-28}$ A contribution of this study is to extend the MDRs literature to AIANs.

The smaller effects of educational attainment on smoking of non-Whites may be due to multiple societal and structural factors. ${ }^{33,34}$ Due to residential segregation, highly educated non-Whites are more likely to live in ethnic enclaves that are higher in stress, poverty, and social disorder and lower in resources. ${ }^{35}$ In addition, due to the labour market discrimination, highly educated ethnic minorities are less likely to secure employment and income. ${ }^{36-38}$ Segregation and lower availability of resources in schools also reduce the effects of educational attainment for people of color, such as Blacks, Hispanics, and AIANs. ${ }^{33,34}$

Predatory marketing practices and availability of tobacco retailers may be other potential mechanisms that cause 
ethnic disparities in tobacco use, particularly through MDRs. Predatory marketing and advertising may disproportionately increase the risk of tobacco use among people of color and ethnic groups across SES levels. The experience of highly educated Whites, however, differs.

\section{Future Research}

The results of the current research are limited to the United States. It is still unknown if MDRs exist outside the US or not. ${ }^{23,}{ }^{33}$ Given the existing cross-national differences in the effects of social determinants of health, ${ }^{39-42}$ there is a need to study whether ethnic disparities in smoking in other countries are at least in part due to diminished returns of SES indicators, particularly educational attainment. Ethnic disparities in smoking have been well described in other countries outside the United States, ${ }^{43}$ and we know that educational level contributes to such disparities across countries. $^{44-48}$ Comparative studies of MDRs across the world are very important, particularly because educational attainment operates differently across countries. ${ }^{39-42}$

\section{Policy Implications}

Policies that tighten tobacco marketing regulations may have a role in reducing MDRs. In this view, introducing more restrictive marketing policies that ban point-of-sale advertising and flavoring for poor areas may not only reduce overall smoking rates but may disproportionately impact ethnic disparities. Future research should test if restricting predatory marketing will reduce tobacco use disparities by ethnicity.

There is a need for policy evaluations to compare national and local policies that can potentially reduce or increase the ethnic and SES disparities in tobacco use, particularly those that are due to MDRs of educational attainment. ${ }^{19,31-33,38,49-53}$ States vary in point-of-sale advertising, discounts, coupons, and flavoring, which may contribute to MDRs for tobacco use. ${ }^{19,32}$ There is a need to study how variation in marketing strategies can undo MDRs ${ }^{19,30-32}$ in communities of color.

\section{Limitations}

This study had some methodological limitations. The crosssectional design of the data does not allow causal inferences. Sample size was imbalanced across ethnic groups. Many SES indicators such as income and wealth were not included. This study was limited to individual level SES, and future research should investigate structural factors such as tobacco policy, density of retails, and area-level SES. Despite these limitations, this is the first study to show MDRs of educational attainment for AIANs. Previous literature has been exclusively limited to Blacks $^{37,49,54-56}$ and Hispanics. ${ }^{21,23,52}$

\section{Conclusion}

In the United States, ethnicity alters the effects of educational attainment on smoking. While highly educated Whites show a very low rate of high-risk behaviors such as smoking, highly educated AIANs continue to smoke, regardless of their educational attainment. The result is additional risk of smoking in highly educated AIANs.

\section{Research Highlights}

\section{What Is Already Known?}

Education protects populations against health risk behaviors such as smoking. It is also known that highly educated Black and Hispanic Americans remain at high risk of smoking, a pattern also known as Minorities Diminshed Returns (MDRs).

\section{What This Study Adds?}

It was found that MDRs also apply to American Indians and Alaska Native (AIAN) individuals. It seems that MDRs are relevant to all marginalized groups.

\section{Authors' Contributions}

SA: conceptualization, data analysis, first draft, revision, and approval. MB: revision and approval.

\section{Conflict of Interest Disclosures}

The authors declare that they have no conflicts of interest.

\section{Ethical Approval}

All adult participants in the NHIS provided informed consent. Westat's Institutional Review Board approved the National Health Interview Survey (NHIS) study protocol.

\section{Funding/Support}

The research reported in this publication was supported by the National Cancer Institute of the National Institute of Health (NIH) and the FDA Center for Tobacco Products (CTP) under Award Number U54CA229974. The content is solely the responsibility of the authors and does not necessarily represent the official views of the NIH or the Food and Drug Administration. Bazargan is supported by the Center for Medicare and Medicaid Services (CMS) Grant 1H0CMS331621 as well as the NIH Awards 54MD008149, R25 MD007610, 2U54MD007598, and U54 TR001627. Assari is also supported by the National Cancer Institute (NCI) grant CA201415-02 (Co-PI = R. Mistry). A publicly available data set was downloaded from the NHIS website at CDC. The NHIS is funded by the CDC.

\section{References}

1. Ellickson PL, Orlando M, Tucker JS, Klein DJ. From adolescence to young adulthood: racial/ethnic disparities in smoking. Am J Public Health. 2004;94(2):293-299. doi:10.2105/ajph.94.2.293.

2. Racial disparities in smoking-attributable mortality and years of potential life lost --- Missouri, 2003-2007. MMWR Morb Mortal Wkly Rep. 2010;59(46):1518-1522.

3. Trinidad DR, Perez-Stable EJ, White MM, Emery SL, Messer K. A nationwide analysis of US racial/ethnic disparities in smoking behaviors, smoking cessation, and cessation-related factors. Am J Public Health. 2011;101(4):699-706. doi:10.2105/ ajph.2010.191668.

4. Soulakova JN, Huang H, Crockett LJ. Racial/Ethnic Disparities in Consistent Reporting of Smoking-Related Behaviors. J Addict Behav Ther Rehabil. 2015;4(4). doi:10.4172/2324-9005.1000147.

5. Blumenthal DS. Racial and ethnic disparities in smoking prevalence in Israel and the United States: progress to date and 
prospects for the future. Isr J Health Policy Res. 2017;6(1):51. doi:10.1186/s13584-017-0177-9.

6. Laveist TA, Thorpe RJ Jr, Mance GA, Jackson J. Overcoming confounding of race with socio-economic status and segregation to explore race disparities in smoking. Addiction. 2007;102 Suppl 2:65-70. doi:10.1111/j.1360-0443.2007.01956.x.

7. Reid JL, Hammond D, Driezen P. Socio-economic status and smoking in Canada, 1999-2006: has there been any progress on disparities in tobacco use? Can J Public Health. 2010;101(1):7378. doi:10.1007/bf03405567.

8. Zhang X, Martinez-Donate AP, Jones NR. Educational disparities in home smoking bans among households with underage children in the United States: can tobacco control policies help to narrow the gap? Nicotine Tob Res. 2013;15(12):1978-1987. doi:10.1093/ ntr/ntt090.

9. Reimer RA, Gerrard M, Gibbons FX. Racial disparities in smoking knowledge among current smokers: data from the health information national trends surveys. Psychol Health. 2010;25(8):943-959. doi:10.1080/08870440902935913.

10. Rock VJ, Davis SP, Thorne SL, Asman KJ, Caraballo RS. Menthol cigarette use among racial and ethnic groups in the United States, 2004-2008. Nicotine Tob Res. 2010;12 Suppl 2:S117-124. doi:10.1093/ntr/ntq204.

11. Terry-McElrath YM, Wakefield MA, Emery $\mathrm{S}$, et al. State anti-tobacco advertising and smoking outcomes by gender and race/ethnicity. Ethn Health. 2007;12(4):339-362. doi:10.1080/13557850701300723.

12. Keeler C, Max W, Yerger V, Yao T, Ong MK, Sung HY. The Association of Menthol Cigarette Use With Quit Attempts, Successful Cessation, and Intention to Quit Across Racial/Ethnic Groups in the United States. Nicotine Tob Res. 2017;19(12):14501464. doi:10.1093/ntr/ntw215.

13. Giovenco DP, Spillane TE, Merizier JM. Neighborhood Differences in Alternative Tobacco Product Availability and Advertising in New York City: Implications for Health Disparities. Nicotine Tob Res. 2019;21(7):896-902. doi:10.1093/ntr/nty244.

14. Anderson SJ. Marketing of menthol cigarettes and consumer perceptions: a review of tobacco industry documents. Tob Control. 2011;20(Suppl 2):ii20-ii28. doi:10.1136/tc.2010.041939.

15. Greaves L, Hemsing N. Women and tobacco control policies: social-structural and psychosocial contributions to vulnerability to tobacco use and exposure. Drug Alcohol Depend. 2009;104 Suppl 1:S121-130. doi:10.1016/j.drugalcdep.2009.05.001.

16. Cokkinides VE, Halpern MT, Barbeau EM, Ward E, Thun MJ. Racial and ethnic disparities in smoking-cessation interventions: analysis of the 2005 National Health Interview Survey. Am J Prev Med. 2008;34(5):404-412. doi:10.1016/j.amepre.2008.02.003.

17. Tran ST, Rosenberg KD, Carlson NE. Racial/ethnic disparities in the receipt of smoking cessation interventions during prenatal care. Matern Child Health J. 2010;14(6):901-909. doi:10.1007/s10995009-0522-x.

18. Assari S, Caldwell CH. Family Income at Birth and Risk of Attention Deficit Hyperactivity Disorder at Age 15: Racial Differences. Children (Basel). 2019;6(1). doi:10.3390/children6010010.

19. Assari S, Farokhnia M, Mistry R. Education Attainment and Alcohol Binge Drinking: Diminished Returns of Hispanics in Los Angeles. Behav Sci (Basel). 2019;9(1). doi:10.3390/bs9010009.

20. Assari S. Family Socioeconomic Position at Birth and School Bonding at Age 15; Blacks' Diminished Returns. Behav Sci (Basel). 2019;9(3). doi:10.3390/bs9030026.

21. Assari S, Mistry R. Diminished Return of Employment on Ever Smoking Among Hispanic Whites in Los Angeles. Health Equity. 2019;3(1):138-144. doi:10.1089/heq.2018.0070.

22. Assari S. Parental Educational Attainment and Academic Performance of American College Students; Blacks' Diminished
Returns. J Health Econ Dev. 2019;1(1):21-31.

23. Assari S. Socioeconomic Determinants of Systolic Blood Pressure; Minorities' Diminished Returns. J Health Econ Dev. 2019;1(1):111.

24. Assari S, Helmi H, Bazargan M. Health Insurance Coverage Better Protects Blacks than Whites against Incident Chronic Disease. Healthcare (Basel). 2019;7(1). doi:10.3390/healthcare7010040.

25. Assari S, Schatten HT, Arias SA, Miller IW, Camargo CA, Boudreaux ED. Higher Educational Attainment is Associated with Lower Risk of a Future Suicide Attempt Among Non-Hispanic Whites but not Non-Hispanic Blacks. J Racial Ethn Health Disparities. 2019;6(5):1001-1010. doi:10.1007/s40615-019-00601-z.

26. Chalian H, Khoshpouri P, Assari S. Patients' age and discussion with doctors about lung cancer screening; Diminished returns of Blacks. Aging Med (Milton). 2019;2(1):35-41. doi:10.1002/ agm2.12053.

27. Assari S. Parental Education Attainment and Educational Upward Mobility; Role of Race and Gender. Behav Sci (Basel). 2018;8(11). doi:10.3390/bs8110107.

28. Assari S. Parental Educational Attainment and Mental Well-Being of College Students; Diminished Returns of Blacks. Brain Sci. 2018;8(11). doi:10.3390/brainsci8110193.

29. Assari S. Educational Attainment Better Protects African American Women than African American Men Against Depressive Symptoms and Psychological Distress. Brain Sci. 2018;8(10). doi:10.3390/ brainsci8100182.

30. Assari S, Lankarani MM. Education and Alcohol Consumption among Older Americans; Black-White Differences. Front Public Health. 2016;4:67. doi:10.3389/fpubh.2016.00067.

31. Assari S, Mistry R. Erratum: Assari, S.; Mistry, R. Educational Attainment and Smoking Status in a National Sample of American Adults; Evidence for the Blacks' Diminished Return. Int. J. Environ. Res. Public Health 2018, 15, 763. Int J Environ Res Public Health. 2018;15(10). doi:10.3390/ijerph15102084.

32. Assari S, Mistry R. Educational Attainment and Smoking Status in a National Sample of American Adults; Evidence for the Blacks' Diminished Return. Int J Environ Res Public Health. 2018;15(4). doi:10.3390/ijerph15040763.

33. Assari S. Unequal Gain of Equal Resources across Racial Groups. Int J Health Policy Manag. 2017;7(1):1-9. doi:10.15171/ ijhpm.2017.90.

34. Assari S. Health Disparities due to Diminished Return among Black Americans: Public Policy Solutions. Soc Issues Policy Rev. 2018;12(1):112-145. doi:10.1111/sipr.12042.

35. Assari S. Parental Education Better Helps White than Black Families Escape Poverty: National Survey of Children's Health. Economies. 2018;6(2):30. doi:10.3390/economies6020030.

36. Assari S, Preiser B, Kelly M. Education and Income Predict Future Emotional Well-Being of Whites but Not Blacks: A Ten-Year Cohort. Brain Sci. 2018;8(7). doi:10.3390/brainsci8070122.

37. Assari S. Life Expectancy Gain Due to Employment Status Depends on Race, Gender, Education, and Their Intersections. J Racial Ethn Health Disparities. 2018;5(2):375-386. doi:10.1007/s40615-0170381-x.

38. Assari S. Blacks' Diminished Return of Education Attainment on Subjective Health; Mediating Effect of Income. Brain Sci. 2018;8(9). doi:10.3390/brainsci8090176.

39. Assari S, Lankarani MM. Does Multi-morbidity Mediate the Effect of Socioeconomics on Self-rated Health? Cross-country Differences. Int J Prev Med. 2015;6:85. doi:10.4103/2008-7802.164413.

40. Assari S. Cross-country variation in additive effects of socioeconomics, health behaviors, and comorbidities on subjective health of patients with diabetes. J Diabetes Metab Disord. 2014;13(1):36. doi:10.1186/2251-6581-13-36.

41. Assari S, Lankarani RM, Lankarani MM. Cross-country differences 
in the association between diabetes and disability. J Diabetes Metab Disord. 2014;13(1):3. doi:10.1186/2251-6581-13-3.

42. Assari S. Cross-Country Differences in the Additive Effects of Socioeconomics, Health Behaviors and Medical Comorbidities on Disability among Older Adults with Heart Disease. J Tehran Heart Cent. 2015;10(1):24-33.

43. Teng $A M$, Atkinson J, Disney $G$, et al. Ethnic inequalities in cancer incidence and mortality: census-linked cohort studies with 87 million years of person-time follow-up. BMC Cancer. 2016;16(1):755. doi:10.1186/s12885-016-2781-4.

44. Barreto SM, de Figueiredo RC, Giatti L. Socioeconomic inequalities in youth smoking in Brazil. BMJ Open. 2013;3(12):e003538. doi:10.1136/bmjopen-2013-003538.

45. Verlato G, Accordini S, Nguyen G, et al. Socioeconomic inequalities in smoking habits are still increasing in Italy. BMC Public Health. 2014;14:879. doi:10.1186/1471-2458-14-879.

46. Doku D, Darteh EK, Kumi-Kyereme A. Socioeconomic inequalities in cigarette smoking among men: evidence from the 2003 and 2008 Ghana demographic and health surveys. Arch Public Health. 2013;71(1):9. doi:10.1186/0778-7367-71-9.

47. Mohsin M, Bauman AE, Forero R. Socioeconomic correlates and trends in smoking in pregnancy in New South Wales, Australia. J Epidemiol Community Health. 2011;65(8):727-732. doi:10.1136/ jech.2009.104232.

48. Eek F, Ostergren PO, Diderichsen F, et al. Differences in socioeconomic and gender inequalities in tobacco smoking in Denmark and Sweden; a cross sectional comparison of the equity effect of different public health policies. BMC Public Health.
2010;10:9. doi:10.1186/1471-2458-10-9.

49. Assari S, Hani N. Household Income and Children's Unmet Dental Care Need; Blacks' Diminished Return. Dent J (Basel). 2018;6(2). doi:10.3390/dj6020017.

50. Assari S, Caldwell CH, Zimmerman MA. Family Structure and Subsequent Anxiety Symptoms; Minorities' Diminished Return. Brain Sci. 2018;8(6). doi:10.3390/brainsci8060097.

51. Assari S, Caldwell CH, Mincy R. Family Socioeconomic Status at Birth and Youth Impulsivity at Age 15; Blacks' Diminished Return. Children (Basel). 2018;5(5). doi:10.3390/children5050058.

52. Assari S. Socioeconomic Status and Self-Rated Oral Health; Diminished Return among Hispanic Whites. Dent J (Basel). 2018;6(2). doi:10.3390/dj6020011.

53. Assari S, Thomas A, Caldwell CH, Mincy RB. Blacks' Diminished Health Return of Family Structure and Socioeconomic Status; 15 Years of Follow-up of a National Urban Sample of Youth. J Urban Health. 2018;95(1):21-35. doi:10.1007/s11524-017-0217-3.

54. Assari S, Lankarani MM. Race and Urbanity Alter the Protective Effect of Education but not Income on Mortality. Front Public Health. 2016;4:100. doi:10.3389/fpubh.2016.00100.

55. Assari S, Moghani Lankarani M. Poverty Status and Childhood Asthma in White and Black Families: National Survey of Children's Health. Healthcare (Basel). 2018;6(2). doi:10.3390/ healthcare6020062.

56. Assari S, Lapeyrouse LM, Neighbors HW. Income and Self-Rated Mental Health: Diminished Returns for High Income Black Americans. Behav Sci (Basel). 2018;8(5). doi:10.3390/bs8050050. 